\title{
Pesquisa de Salmonella spp. e oocisto de Eimeria spp. em frangos tipo caipira destinados a alimentação escolar no Município de São Luís, MA
}

Research of Salmonella spp. and oocyst of Eimeria spp. in free-range chickens it provides school feeding in the City of São Luís, MA

La investigación de Salmonella spp. y oocisto de Eimeria spp. en pollos de corral destinados la alimentación escolar en la Ciudad de São Luís, MA

Recebido: 11/06/2021 | Revisado: 24/06/2021 | Aceito: 28/06/2021 | Publicado: 12/07/2021

Swênia Christina Pinheiro Soares

ORCID: https://orcid.org/0000-0003-3000-0629 Instituto Federal de Educação, Ciência e Tecnologia do Maranhão, Brasil E-mail: sweniach@gmail.com

Daniela Aguiar Penha Brito ORCID: https://orcid.org/0000-0002-5190-0792 Instituto Federal de Educação, Ciência e Tecnologia do Maranhão, Brasil E-mail: danielabrito@ifma.edu.br

Danilo Rodrigues Barros Brito ORCID: https://orcid.org/0000-0001-5073-3681 Instituto Federal de Educação, Ciência e Tecnologia do Maranhão, Brasil E-mail: danilobrito@ifma.edu.br

Naliane Silva Castro

ORCID: https://orcid.org/0000-0002-2269-3958

Instituto Federal de Educação, Ciência e Tecnologia do Maranhão, Brasil E-mail: nalianecastro@acad.ifma.edu.br

\begin{abstract}
Resumo
A avicultura de frango tipo caipira difundiu-se de forma ampla em todo país. Apesar das características de rusticidade, essas aves são suscetíveis a doenças graves como as salmoneloses e a coccidiose aviária. Objetivou-se pesquisar os agentes infecciosos dessas doenças em frangos caipiras destinados a alimentação escolar no município de São Luís, MA. Procedeu-se o exame clínico de 198 aves, que consistiu na observação da aparência da plumagem, bico, cristas, região da cloaca e condição corporal. As amostras foram analisadas para pesquisa de Salmonella spp. seguindo a metodologia do Ministério da Agricultura, Pecuária e Abastecimento. Das 99 amostras de cloaca (pool de duas aves), coletadas para pesquisa de Salmonella spp., $10(10,1 \%)$ amostras foram suspeitas para a bactéria nas provas bioquímicas, porém todas foram negativas $(0 \%)$ por sorotipificação antigênica. Na pesquisa e contagem de oocistos de Eimeria spp. foi utilizado o método de centrífugo-flutuação em solução de sacarose. Na contagem de oocistos de Eimeria spp., das 124 amostras coletadas de intestino durante a evisceração, $92(74,19 \%)$ amostras apresentaram oocistos do parasita, com contagens variando de 100 a 18.800 oocistos. Os resultados foram considerados esperados visto que em sistema de criação de frangos caipiras, onde não se utiliza drogas cocciostáticas, a prevalência de Eimeria spp. é frequentemente elevada. Portanto, pode-se concluir que os frangos de corte tipo caipira destinados ao abatedouro no município de São Luís não apresentaram isolamento para Salmonella spp., porém tiveram alta ocorrência de infecção por oocisto de Eimeria spp.
\end{abstract}

Palavras-chave: Salmonelose; Eimeriose; Abate; Avicultura; Suabe cloacal.

\begin{abstract}
Poultry farming has spread widely across the country. Despite their rustic characteristics, these birds are susceptible to serious diseases such as salmonellosis and avian coccidiosis. The objective was to investigate the infectious agents of these diseases in free-range chickens destined for school feeding in the city of São Luís, MA. A clinical examination of 198 birds was carried out, which consisted of observing the appearance of the plumage, beak, ridges, cloaca region and body condition. The samples were analyzed for Salmonella spp. following the methodology of the Ministry of Agriculture, Livestock and Supply . Of the 99 samples of cloaca (group of two birds), collected for investigation of Salmonella spp., $10(10.1 \%)$ samples were suspected of the bacterium in biochemical tests, however all were negative $(0 \%)$ due to antigenic serotyping. The survey and enumeration of Eimeria spp. The centrifugal flotation method was used in a sucrose solution. In the count of Eimeria spp. Oocysts, Of the 124 samples collected from the intestine during evisceration, 92 (74.19\%) presented oocysts of the parasite, with counts ranging from 100 to 18,800 oocysts. The results were considered expected since, in a free-range chicken breeding system, where cocciostatic drugs are not
\end{abstract}


used, the prevalence of Eimeria spp. it is often high. Therefore, it can be concluded that free-range chickens destined for slaughter in the municipality of São Luís did not present isolation for Salmonella spp., But did have a high incidence of infection by Eimeria spp.

Keywords: Salmonellosis; Eimeriosis; Slaughter; Poultry; Cloacal swab.

\section{Resumen}

La avicultura se ha extendido ampliamente por todo el país. A pesar de sus características rústicas, estas aves son susceptibles a enfermedades graves como la salmonelosis y la coccidiosis aviar. El objetivo fue investigar los agentes infecciosos de estas enfermedades en pollos de corral destinados a alimentación escolar en la ciudad de São Luís, MA. Se realizó un examen clínico de 198 aves, que consistió en observar la apariencia del plumaje, pico, crestas, región cloaca y condición corporal. Las muestras fueron analizadas para Salmonella spp. siguiendo la metodología del Ministerio de Agricultura, Ganadería y Abastecimiento. De las 99 muestras de cloaca (grupo de dos aves), recolectadas para la investigación de Salmonella spp., 10 (10.1\%) muestras fueron sospechosas de la bacteria en pruebas bioquímicas, sin embargo todas fueron negativas $(0 \%)$ debido a serotipificación antigénica. La prospección y enumeración de Eimeria spp. Se utilizó el método de flotación centrífuga en una solución de sacarosa. En el recuento de oocistos de Eimeria spp., De las 124 muestras recolectadas del intestino durante la evisceración, 92 (74,19\%) presentaron ooquistes del parásito, con recuentos que variaron de 100 a 18.800 ooquistes. Los resultados se consideraron esperados ya que, en un sistema de cría de pollos de corral, donde no se utilizan fármacos cocciostáticos, la prevalencia de Eimeria spp. a menudo es alto. Por lo tanto, se puede concluir que los pollos de corral destinados al sacrificio en el municipio de São Luís no presentaron aislamiento para Salmonella spp., Pero sí tuvieron una alta incidencia de infección por Eimeria spp.

Palabras clave: Salmonelosis; Eimeriosis; Sacrificio; Aves de corral; Hisopado cloacal.

\section{Introdução}

O consumo de carne de frango tem aumentado substancialmente nas duas últimas décadas, impulsionando a avicultura de corte brasileira e consolidando o país como maior exportador e terceiro maior produtor de carne de frango no mundo (ABPA, 2021). A criação de frangos tipo caipira para a produção de carne é um dos segmentos da avicultura de corte que tem se expandido, atendendo uma fatia de mercado composta por consumidores que demandam por produtos mais saudáveis e com características diferenciadas de textura e coloração da carne (Caires et al., 2010).

A avicultura de corte caipira é uma atividade intensamente difundida em núcleos agrícolas familiares, que utiliza um sistema que preza pelo bem-estar animal e que gera fonte de alimento de boa qualidade e renda econômica para os produtores (Morais et al., 2015). A utilização de linhagens de aves de crescimento lento, rústicas, com acesso a piquetes com área verde para o exercício diário e a ração sem acréscimos de aditivos melhoradores de desempenho são características marcantes do sistema de criação caipira (Brasil, 2012; Takahashi et al., 2006). Apesar da rusticidade, frangos tipo caipiras são suscetíveis a doenças graves que provocam perdas econômicas para o setor avícola como as salmoneloses, causada por bactérias do gênero Salmonella, e coccidiose, causada por protozoários do gênero Eimeria (Silva et al., 2015).

A salmonelose aviária refere-se ao grupo de doenças agudas ou crônicas de aves provocada pelo agente patogênico Salmonella, existindo três formas de manifestação: a pulorose, causada pela Salmonella Enterica sorovar Pullorum, o tifo aviário, causado pela Salmonella Enterica sorovar Gallinarum, e o paratifo aviário, causado pelos demais sorovares de Salmonella enterica (Barrow \& Mether, 2013). Este último é a salmonelose aviária de maior importância para cadeia produtiva de carnes, caracterizando-se por provocar, na maioria dos casos, infecções subclínicas, possibilitando a permanência da bactéria no trato digestório dos frangos até o abate (Andino; Hannig, 2015; Cardoso et al., 2015; Barrow et al., 2012). O estado de portador é o fator epidemiológico mais relevante do paratifo, o que converte as aves em uma fonte contínua de contaminação para o meio ambiente e para os produtos de origem animal, favorecendo a introdução das salmonelas na cadeia alimentar (Anvisa, 2011; Hue et al., 2011).

A carne de frango e ovos contaminados são considerados os alimentos mais comuns de introduzir a bactéria Salmonella spp. na cadeia alimentar do ser humano, de forma que o consumo, sem tratamento térmico adequado tornou-se um dos fatores de risco para salmoneloses humanas, tendo relevância a saúde pública (Yu et al., 2016). Os estudos realizados no 
Brasil mostram baixa prevalência da Salmonella enterica em aves e no ambiente de criação de galinhas caipiras (Gomes Filho et al., 2014; Alcântara, 2015; Rossi \& Bampi, 2015), quando comparadas com o sistema de criação do frango industrial (Brito, 2016). No entanto, o abate e processamento da carne sem condições higiênicas adequadas pode ser um fator de risco para contaminação por Salmonella spp., caso existam aves infectadas (Hue et al., 2011).

$\mathrm{Na}$ avicultura caipira, a coccidiose é considerada uma das doenças que pode provocar perdas econômicas mundiais significativas, devido a episódios de diarreia e mortes em animais jovens, ou ainda pode causar infecções subclínicas, que afetam o desempenho produtivo das aves comerciais (Gazoni, 2014; Kaboudi et al., 2016). Trata-se de uma infecção intestinal causada por protozoários, parasitas intracelulares, formadores de coccídeos, sendo o gênero Eimeria o de maior importância clínica (Luchese et al., 2007). Em sistema de criação de frangos caipiras, a prevalência de Eimeria spp. é considerada endêmica (Siqueira Marques, 2016; Moraes et al., 2013; Fichina et al., 2012), podendo provocar prejuízos a produção. A não utilização de drogas coccidiostáticas e o manejo sanitário feito de forma inadequada podem contribuir para a disseminação de oocistos nas granjas e a alta ocorrência em aves (Hornink \& Kawazoe, 2020; Luchese et al., 2007).

No estado do Maranhão, a carne de frangos tipo caipira é um alimento de alto valor biológico, que faz parte da culinária regional, sendo destinada a alimentação de estudantes de escolas públicas, a partir do Programa Nacional de Alimentação Escolar (PNAE). Este abrange a compra de gêneros alimentícios diretamente da agricultura familiar ou produtor familiar rural, apoiando o uso de alimentos regionais e incentivando o desenvolvimento sustentável da avicultura de corte caipira na região (Brasil, 2009). Para que se produza alimentos saudáveis e seguros, é primordial o controle de doenças das aves que possam afetar o desempenho zootécnico e a qualidade sanitária dos produtos de origem aviária (Santos et al., 2013). Assim, objetivou-se estudar o perfil sanitário e a ocorrência de Salmonella spp. e oocistos de Eimeira spp. em frangos tipo caipira destinados a alimentação escolar no município de São Luís, Maranhão.

\section{Metodologia}

\section{Caracterização do perfil sanitário da criação de frangos caipiras}

A pesquisa foi conduzida no abatedouro avícola do Instituto Federal de Educação, Ciência e Tecnologia do Maranhão (IFMA), Campus Maracanã, sob Serviço de Inspeção Municipal (S.I.M.), localizado no município de São Luís, Estado do Maranhão. Foram coletadas e analisadas amostras de lotes de frangos tipo caipira de pequenos e médios criadores da Região Metropolitana de São Luís, que destinam o abate das aves no local de estudo, e fazem parte do Programa Nacional de Alimentação Escolar (PNAE). A pesquisa foi submetida e aprovada pela comissão de ética no uso de animais em ensino e pesquisa (CEUA) do IFMA sob nº2/2019.

Depois de esclarecidos os objetivos da pesquisa, foi aplicado um questionário epidemiológico junto a três proprietários das aves, obtendo informações sobre o perfil sanitário e outros aspectos da produção das aves: o sistema de criação (extensivo, semi-intensivo, densidade do lote), características das aves (raça/linhagem, idade de abate), manejo sanitário (programa de vacinação, uso de medicamentos, medidas sanitárias adotadas, relatos de doenças na produção), manejo alimentar (programas de alimentação, tipos de ração, uso de coccidiostáticos, acesso a piquetes) e aspectos da comercialização (destino da produção, valor do produto). Os dados obtidos foram avaliados utilizando-se a estatística descritiva, calculando-se a frequência absoluta e relativa.

\section{Coleta das amostras}

Foram acompanhados o abate de três lotes de frangos caipiras ocorridos no mês de novembro de 2018, fevereiro e março de 2019 no abatedouro do IFMA, campus Maracanã. Durante a etapa pré-abate, foi realizado um exame clínico de 198 aves vivas, sendo selecionadas de forma aleatória, quatro aves de cada caixa de transporte do lote. Estas foram submetidas a 
um exame clínico geral, que consistiu na observação da aparência da plumagem, bico, cristas, região da cloaca e condição corporal.

Para a pesquisa de Salmonella spp., após o exame, foram coletadas 99 amostras da cloaca, através do uso de um suabe estéril, sendo que uma amostra correspondeu a um pool de dois suabes cloacais, sendo estes acondicionados em tubos contendo água peptonada tamponada a $0,1 \%$. Foram coletadas 8 amostras de fezes depositadas nas caixas de aves vivas no préabate, através do uso de uma espátula estéril e acondicionadas em frasco plástico estéril. As amostras foram identificadas e transportadas, em caixas isotérmicas com gelo reciclável, até o Laboratório de Microbiologia do IFMA, Campus Maracanã, onde foram imediatamente analisadas.

Para a análise parasitológica de contagem de oocistos de Eimeria spp. durante o abate, foram coletadas, de forma aleatória, 124 amostras de intestino, sendo acondicionadas em sacos plásticos e transportados para o Laboratório de Sanidade Animal do IFMA, Campus Maracanã, onde foram imediatamente analisadas.

\section{Análise microbiológica}

As amostras de suabe cloacal e de fezes foram analisadas para pesquisa de Salmonella spp. seguindo a metodologia do Ministério da Agricultura, Pecuária e Abastecimento (Brasil,1995). Para o pré-enriquecimento, as amostras de suabe de cloaca foram imediatamente incubados à $37^{\circ} \mathrm{C}$ por 18 a 20 horas. Das amostras de fezes, foram pesadas $25 \mathrm{~g}$ e transferidos, assepticamente, para $225 \mathrm{~mL}$ de água peptonada a 1\%, e então incubadas a mesma temperatura e tempo das demais amostras.

Após esse período, seguiu-se para a etapa de enriquecimento, que consistiu em transferir na proporção 1:10 para caldo Selenito-Cistina $(1 \mathrm{~mL} / 10 \mathrm{~mL})$ e 1:100 para caldo Rappaport Vassiliadis $(0,1 \mathrm{~mL} / 10 \mathrm{~mL})$, e então, os tubos foram incubados à $37^{\circ} \mathrm{C}$ durante 18 a 24 horas. Posteriormente, as amostras foram semeadas em meios indicadores seletivos: Agar Xilose Lisina Desoxicolato (XLD) e Agar Verde Brilhante Vermelho De Fenol Lactose Sacarose (BPLS). Após a incubação a $37^{\circ} \mathrm{C}$ por 24 horas, as colônias suspeitas de Salmonella spp. foram isoladas e transferidas para tubos contendo ágar nutriente, no qual foram incubadas à $37^{\circ} \mathrm{C}$ por 24 horas. Do estoque de crescimento, as amostras foram submetidas aos testes bioquímicos em ágar Tríplice Açúcar Ferro (TSI), Agar Lisina Ferro (LIA), SIM e caldo ureia. As cepas que apresentaram perfil bioquímico compatível com o gênero Salmonella foram caracterizadas antigenicamente através do teste de aglutinação rápida com soro anti-somático O polivalente de Salmonella. Os isolados suspeitos para Salmonella foram cultivados em ágar nutriente e remetidos ao Laboratório de Enterobactérias da Fundação Instituto Oswaldo Cruz, Rio de Janeiro (IOC/FIOCRUZ, RJ, BRASIL) para a sorotipificação antigênica.

\section{Análise parasitológica}

Para pesquisa e contagem de oocistos de Eimeria spp. foi utilizado o método de centrífugo-flutuação em solução de sacarose segundo Sheather (1928), sendo os oocistos visualizados, identificados e contados, com uso de microscópio óptico, em objetiva 10x.

\section{Resultados e Discussão}

As aves destinadas ao abatedouro no município de São Luís eram frangos caipiras da linhagem Color Plume (CPK), com idade entre 80 a 114 dias de vida, vacinadas contra Newcastle e Bouba aviária, criadas em sistema semi-intensivo, com acesso a piquetes e aviário com densidade de 6 a 8 aves $/ \mathrm{m}^{2}$. A alimentação fornecida às aves era exclusivamente de origem vegetal, à base de milho, farelo de soja e pasto. Quanto ao manejo sanitário, segundo os produtores, adotavam uma higienização regular com uso de desinfetantes a base de hipoclorito de sódio ou cresóis, além de lavagem dos bebedouros e 
comedouros diariamente. A respeito do controle de coccidiose, dois produtores relataram ter utilizado medicamentos à base de terramicina e/ou ormetoprim associado a sulfadimetoxina.

O sistema de produção para frangos de corte tipo caipira é normatizado pelo ofício circular DOI/DIPOA n 007/99 de 19/05/99 do Ministério da Agricultura, Pecuária e do Abastecimento (MAPA, 1999), que trata do registro do produto Frango Caipira ou Colonial. De acordo com as diretrizes do documento, a produção de frangos caipiras deve utilizar linhagens próprias, de crescimento lento, para chegar ao peso ideal de abate com a idade mínima de 85 dias, que os pintos devem ter acesso ao pasto a partir dos 25 dias de idade e que em nenhuma fase da vida sejam alimentados com rações contendo promotores de crescimento, nem subprodutos de origem animal, como farinhas de carne, por exemplo. Adicionalmente, foi publicado o Ofício Circular DIPOA No 02/2012 (MAPA, 2012) que preconiza a redução do tempo de abate em 14 dias, passando então para 70 dias. Conforme essas recomendações, todos os lotes de frangos avaliados para o abate enquadraram-se quanto ao registro do tipo caipira ou colonial, em relação ao sistema de criação, alimentação e tempo de abate.

O gráfico 1 apresenta os aspectos clínicos observados de aparência normal e anormal de 198 aves avaliadas antes da coleta de amostras. Verificou-se que a maioria das aves aparentava estado clínico sanitário considerado adequado para o abate, sendo que 83,33\% (165/198) apresentaram peso considerado esperado para o abate, 88,89\% (176/198) tinham plumagem limpa e brilhosa, 93,43\% (185/198) apresentaram pata e bico com superfícies íntegras e tonalidade amarela intensa, 90,91\% (180/198) tinham a crista e barbelas avermelhadas e 85,86\% (170/198) possuíam a região cloacal limpa.

Gráfico 1 - Classificação das características clínicas de 198 frangos caipiras destinados ao abatedouro sob Serviço de Inspeção Municipal (S.I.M.), do município de São Luís, 2018 e 2019.

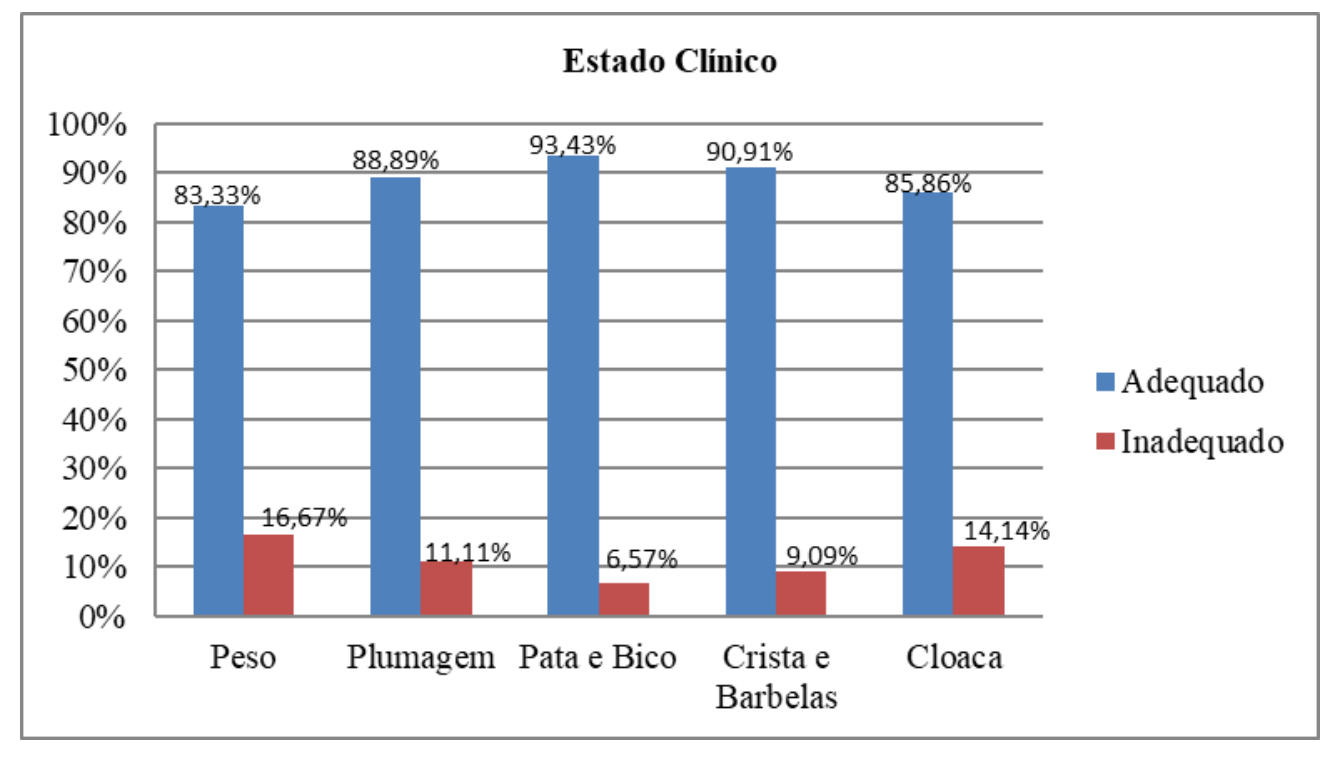

Fonte: Autores.

No exame clínico, foram consideradas características externas para observação das aves com sintomas clínicos de infecções por Salmonella spp. e coccidiose. Em apenas uma ave foi observado que a plumagem estava suja e opaca, tinha baixo peso e região cloacal suja de fezes com aspecto ralo e esbranquiçado, sinais de enterite infecciosa que pode ser provocada por salmonelose ou eimeriose. Salmonella enterica subespécie enterica sorotipo Pullorum (SP) é o agente etiológico causador da doença aviária pulorose conhecida como diarreia bacilar branca ou diarreia branca, entre outros sintomas estão, diminuição no consumo de ração, baixo ganho de peso, eriçamento das penas, crista pálida e retraída, apatia e 
desidratação (Chen et al., 2020; Wang et al., 2012). Estado semelhante pode ser visto em frangos com eimeriose, podendo apresentar debilidade, perda de peso, fezes aquosas e penas eriçadas (Hornink \& Kawazoe, 2020).

Nas análises microbiológicas para isolamento de Salmonella spp., 10 (5,05\%) das 198 amostras coletadas de suabe cloacal apresentaram colônias bacterianas suspeitas, porém na sorotipificação antigênica foram negativos para Salmonella spp. para sorovares de importância para avicultura (Tabela 1). Os isolados foram de Pseudomonas aeruginosa, Morganella morganii, Klebsiella pneumoniae e Proteus mirabilis. Não foi isolada Salmonella spp. em amostras de fezes das aves.

Tabela 1: Detecção de Salmonella spp. em suabe cloacal e oocistos de Eimeira spp. em intestinos de frangos tipo caipira destinados a alimentação escolar, São Luís, MA

\begin{tabular}{ccc}
\hline Produtor familiar rural & \multicolumn{2}{c}{ Frequência de agentes patogênicos } \\
\cline { 2 - 3 } & & Salmonella spp. \\
\hline A & $0(0 / 44)$ & $73,17 \%(30 / 41)$ \\
B & $0(0 / 30)$ & $76,19 \%(32 / 42)$ \\
C & $0(0 / 25)$ & $73,17 \%(30 / 41)$ \\
Total & $0(0 / 99)$ & $74,19 \%(92 / 124)$ \\
\hline
\end{tabular}

Fonte: Autores.

Os resultados negativos para Salmonella spp. em frangos caipiras podem estar relacionados a menor ocorrência da bactéria em aves de sistema de produção caipira quando comparado com aves em sistemas de criação intensivo (Wang et al., 2012). Resultados semelhantes foram encontrados por Silva et al. (2015) que não detectaram frangos caipiras sororeagentes a Salmonella enterica Gallinarum e Pullorum em abatedouro na região do Triângulo Mineiro-MG. Rossi e Bampi (2015) compararam a presença de Salmonella spp. em aves caipiras e aves de granja através do método de suabe cloacal, e isolaram a bactéria em 6,25\% das aves em sistema intensivo, porém não detectaram a bactéria em amostras de aves em sistema caipira. Conforme os autores, o sistema de criação para frangos tipo caipira pode representar menor risco de transmissão de salmonelas entre as aves, reduzindo os riscos de contaminação da cadeia produtiva.

A ausência de isolamento de Salmonella spp. pela análise microbiológica pode ainda ser explicada pela menor eliminação da bactéria em aves em idade de abate. Em estudo da persistência Salmonella enterica Enteritidis em aves aparentemente saudáveis, Andrade et al. (2007) constataram que a frequência de excreção fecal declinou com a idade de aves infectadas, dificultando o isolamento da bactéria nas excretas. Conforme os autores o suabe cloacal como método de monitoramento da excreção de Salmonella apresenta limitações, porque esse patógeno tem a habilidade de ser excretado de forma intermitente e pode ser eliminado em pequenas quantidades pelas fezes, o que dificulta sua detecção. Acrescenta-se que os sistemas de criação de aves em menor densidade podem exercer menores taxas de colonização, excreção e transmissão de Salmonella de importância para saúde pública (Gast et al., 2017).

A salmonelose é uma das zoonoses com maior impacto em relação a saúde pública, devido à alta endemicidade e morbidade (Silva et al., 2019). Devido sua relevância, existem planos nacionais avícolas de combate a salmonelas paratíficas aplicadas a cadeia produtiva, tanto no âmbito da produção das aves (Brasil, 2016), quanto nos produtos de origem avícola (Brasil, 2019). Assim, os resultados de negatividade de Salmonella spp. em frangos caipiras estão de acordo com o recomendado para a saúde animal, indicando baixo risco de contaminação da carne destinada a alimentação escolar. 
No que diz respeito a análise parasitológica para pesquisa de Eimeria spp., do total de 124 amostras de intestino de frangos caipiras, $92(74,19 \%)$ tiveram a presença do agente (Tabela 1), com contagens que variaram de 100 a 18.800 oocistos por amostra. Os resultados indicam a alta ocorrência de aves infectadas por Eimeria spp., sendo considerados superiores aos estudos de ocorrência de oocistos do parasita em frangos caipiras nas cidades de Porto Alegre, RS, no Brasil (55,4\%; Siqueira e Marques, 2016), Shidi Tab, na Tunísia (31,8\%; Kaboudi et al., 2016) e província de KwaZulu-Natal, África do Sul (59,5\%; Fatoba et al., 2020).

Apesar da alta ocorrência de oocistos de Eimeira spp. em amostras de intestinos de frangos caipiras, as manifestações clínicas foram ausentes (Gráfico 1), corroborando de que a coccidiose subclínica é predominante em aves de sistemas caipiras (Kaboudi et al., 2016; Fatoba et al., 2020). O grau de severidade da coccidiose depende da carga parasitária, da capacidade imunológica, idade do hospedeiro e patogenicidade do parasita, relacionado principalmente a espécie de Eimeira (QuirozCastañeda e Dantán-González, 2015). Mesmo de forma subclínica, a coccidiose provoca redução na eficiência metabólica e imunológica da ave, não percebidas pelo produtor (Pinheiro et al., 2014). Os métodos de exames laboratoriais baseados na pesquisa de ovos e oocistos nas fezes de aves domésticas devem ser incentivados e realizados a fim de contribuir para o estabelecimento de controle estratégico em criações extensivas e semi-intensivas (Pinheiro et al., 2014).

\section{Conclusão}

Os frangos de corte tipo caipira destinados a alimentação escolar no município de São Luís não apresentaram isolamento para Salmonella spp., indicando baixo risco de contaminação ambiental e da carne. No entanto, a alta frequência de aves infectadas por oocisto de Eimeria spp., indica a necessidade de adotar controle estratégico antiparasitário das aves caipiras para melhor desempenho produtivo.

\section{Agradecimentos}

Agradecemos ao Instituto Federal do Maranhão - IFMA e à Fundação de Amparo à Pesquisa e ao Desenvolvimento Científico e Tecnológico do Maranhão - FAPEMA, pelo apoio financeiro na execução desta pesquisa.

\section{Referências}

ABPA (2021) - Associação brasileira de proteína animal. (Relatório anual Núm. 21). ABPA.

Alcântara, J. B. (2015). Pesquisa de Salmonella sp. em aves criadas em sistema industrial e alternativo. Tese (Ciência Animal), apresentada para a obtenção do grau de doutora em Ciência Animal. Escola de Veterinária e Zootecnia da Universidade Federal de Goiás, Goiânia.

Andino, A. \& Hanning, I. (2015). Salmonella enterica: Survival, Colonization, and Virulence Differences among Serovars. The Scientific World Journal, 2015(520179), 16. 10.1155/2015/520179.

Andrade, M. A., Mesquita, A. J. de, Stringhini, J. H., Chaves, L. da S., Mattos, M. S., Oliveira, A. S. C. \& Moraes, D. M. C. (2007). Excreção fecal de Salmonella Enteritidis em duas linhagens de frangos de corte. https://www.revistas.ufg.br/vet/article/view/2697.

Anvisa (2011). Ministério da Saúde. Secretaria de Vigilância em Saúde. Manual técnico de diagnóstico laboratorial de Salmonella spp.: diagnóstico laboratorial do gênero Salmonella / Ministério da Saúde. Secretaria de Vigilância em Saúde, Fundação Oswaldo Cruz. Laboratório de Referência Nacional de Enteroinfecções Bacterianas, Instituto Adolfo Lutz. Ministério da Saúde.

Bambi, J., Bambi, M., Biassoto, A., Duarte, E., Secco, R., Wichinovski, V., Mahl, D.L., Pierozan, M. K., Ranghetti, A.L., Rocha, A. A., Rose, T. \& Urio, E.A. (2015). Análise cloacal e comparação de microbiota de galinhas caipiras e frangos de granja.RAMVI, Getúlio Vargas. https://ptdocz.com/doc/1117764/an\%C3\%A1lise-cloacal-e-compara\%C3\%A7\%C3\%A3o-de .

Barrow, P. A., Jones, M. A., Smith, A. L. \& Wigley, P. (2012). The long view: Salmonella--the last forty years. Boston: Avian pathology: journal of the W.V.P.A.

Barrow, P.A. \& Methner, U. (2013). Salmonella in domestic animals. (2a ed.), Cabi Head Office.

Brasil (1995). Ministério da Agricultura, Pecuária e do Abastecimento. Portaria ${ }^{\circ} 126$, de 03 de novembro de 1995 . Normas Técnicas para Controle e Certificação de Núcleos e Estabelecimentos Avícolas como Livres de Salmonella Gallinarum e de Salmonella Pullorum e Livres ou Controlados para 
Salmonella Enteritidis e para Salmonella Typhimurium. Diário Oficial da União, Brasília. Seção 1, p. 3. Recuperado:29/05/2021. Secretaria de Agricultura e Abastecimento, Coordenadoria de Defesa Agropecuária. https://www.defesa.agricultura.sp.gov.br/legislacoes/portaria-sda-126-de-03-11-1995,372.html.

Brasil. (2009). Ministério da Agricultura, Pecuária e Abastecimento. Instrução Normativa no 10, de 11 de abril de 2013 . Diário Oficial da República Federativa do Brasil, Poder Executivo, Brasília, DF, 12 abr. 2012. Seção 1. Defini o programa de gestão de risco diferenciado e complementa a Instrução Normativa MAPA $\mathrm{n}^{\mathrm{o}} 59$, de 02 de dezembro. DIÁRIO OFICIAL DA UNIÃO. https://www.in.gov.br/materia//asset_publisher/Kujrw0TZC2Mb/content/id/30436854/do1-2013-04-12-instrucao-normativa-n-10-de-11-de-abril-de-2013-30436850.

Brasil (2012). Ministério da Agricultura, Pecuária e Abastecimento. Departamento de Inspeção de Produtos de Origem Animal/ divisão de operações industriais. Ofício Circular DOI/DIPOA n ${ }^{\circ}$ 02/2012. Registro do Produto "Frango Caipira ou Frango Colonial" ou "Frango Tipo ou Estilo 25 Caipira" ou “Tipo ou Estilo Colonial”. Diário Oficial da União, Brasília, DF, 01 de fevereiro. https://www.agencia.cnptia.embrapa.br/Repositorio/Oficio-circular-7-de-19de-maio-de-1999_000gy48rvu302wx7ha0b6gs0xgpnhnya.pdf

Brasil (2016). Ministério da Agricultura, Pecuária e Abastecimento. Secretaria de Defesa Agropecuária Instrução Normativa n ${ }^{\circ}$ - 20 , de 21 de outubro de 2016. Art. $1^{\circ}$ Ficam estabelecidos o controle e o monitoramento de Salmonella spp. nos estabelecimentos avícolas comerciais de frangos e perus de corte e nos estabelecimentos de abate de frangos, galinhas, perus de corte e reprodução, registrados no Serviço de Inspeção Federal (SIF), com objetivo de reduzir a prevalência desse agente e estabelecer um nível adequado de proteção ao consumidor, na forma desta Instrução Normativa e dos seus Anexos I a IV, 21 DE OUTUBRO DE 2016, https://www.in.gov.br/materia/-/asset_publisher/KujrwOTZC2Mb/content/id/22061817/do1-2016-10-25-instrucao-normativa-n-20-de21-de-outubro-de-2016-22061778-22061778.

Brasil (2019). Ministério da Agricultura, Pecuária e Abastecimento. Instrução normativa n 60, de 23 de dezembro de 2019 . Estabelece as listas de padrões microbiológicos para alimentos. A Diretoria Colegiada da Agência Nacional de Vigilância Sanitária, no uso das atribuições que lhe confere o art. 15, III e IV, aliado ao art. $7^{\circ}$, III e IV, da Lei n. ${ }^{\circ} 9.782$, de 26 de janeiro de 1999 , e ao art. 53, VI, $\$ \S 1^{\circ}$ e $3^{\circ}$ do Regimento Interno aprovado pela Resolução da Diretoria Colegiada - RDC n ${ }^{\circ} 255$, de 10 de dezembro de 2018, em reunião realizada em 17 de dezembro de 2019. https://www.in.gov.br/en/web/dou/-/instrucaonormativa-n-60-de-23-de-dezembro-de-2019-235332356\#: :text=de\%202019\%2C\%20resolve\%3A-,Art.,prontos\%20para\%20ofert a\%20ao\%20consum idor.\&text $=\% \mathrm{C} 2 \% \mathrm{~A} 7 \% 202 \% \mathrm{C} 2 \% \mathrm{BA} \% 20 \mathrm{~A} \% 20$ investiga $\% \mathrm{C} 3 \% \mathrm{~A} 7 \% \mathrm{C} 3 \% \mathrm{~A} 3 \mathrm{o} \% 20 \mathrm{de}$,diretrizes $\% 20 \mathrm{do} \% 20 \mathrm{Minist} \% \mathrm{C} 3 \% \mathrm{~A} 9 \mathrm{rio} \% 20 \mathrm{da} \% 20 \mathrm{Sa} \% \mathrm{C} 3 \% \mathrm{BAde}$.

Brito, D. A. P. (2016). Aspectos epidemiológicos e perfil de resistência antimicrobiana de Salmonella enterica isoladas da cadeia produtiva de 20 frangos da Mesorregião Norte do Estado do Maranhão. 2016. Tese (Doutorado em Ciência Animal) - Universidade Estadual de Londrina, Londrina.

Caires, C. B., Carvalho, A. P. \& Caires, R. M. (2010). Criação Alternativa de Frangos de Corte. Revista Eletrônica. https://www.yumpu.com/pt/document/view/10089713/criacao-alternativa-de-frangos-de-corte-nutritime.

Cardoso, A. L. S. P., Kanashiro, A. M. I., Stoppa, G. F. Z., Castro, A. G. M. DE. \& Luciano, R. L. (2015). Ocorrência de Salmonella spp. em carcaças de frango provenientes de abatedouros do estado de São Paulo, Brasil, no período de 2000 a 2010. Cienc. Rural, 38 (9), https://doi.org/10.1590/S010384782008005000011

Castañeda, R. E. Q. \& González, E. D. (2015). Control of Avian Coccidiosis: Future and Present Natural Alternatives. Hindawi Publishing Corporation BioMed Research International, 2015 (430610), 11. http://dx.doi.org/10.1155/2015/430610.

Chen, C., Li, J., Zhang, H., Xie, Y., Xiong, L., Liu, H., \& Wang, F. (2020). Effects of a probiotic on the growth performance, intestinal flora, and immune function of chicks infected with Salmonella pullorum. Poultry Science, 99(11), 5316-5323. https://doi.org/10.1016/j.psj.2020.07.017.

Fatoba, A. J., Zishiri, O. T., Blake, D. P., Peters, S. O., Lebepe, J., Mukaratirwa, S. \& Adeleke, M. A. (2020). How to cite this article: Fatoba, A.J., Zishiri, O.T., Blake, D.P., Peters, S.O., Lebepe, J., Mukaratirwa, S., et al. 2020, 'Study on the prevalence and genetic diversity of Eimeria species from broilers and free-range chickens in KwaZulu-Natal province, South Africa', Onderstepoort Journal of Veterinary Research 87(1), 1837. https://doi.org/10.4102/ojvr.v87i1.1837.

Fichina, T., Marchini, C. F. P. \& Cintra, J. A. (2012). Prevalence of intestinal parasites oncommercialandfree-range broilerchickensfrommicro-region of SãoSebastião do Paraíso, MG. Recuperado: 17 de maio, Anais...World'sPoultry Science Journal, Supplement, Salvador, Brazil: https://www.researchgate.net/publication/283215379_PREVALENCE_OF_INTESTINAL_PARASITES_ON_COMMERCIAL_AND_FREE-

RANGE_BROILER_CHICKENS_FROM_MICRO-REGION_OF_SAO_SEBASTIAO_DO_PARAISO_MG.

Gast, R. K., Guraya, R., Jones, D. R., Anderson, K. E. \& Karcher, D. M. (2017). Frequency and Duration of Fecal shedding of Salmonella enteritidis by experimentally infected laying hens housed in enriched colony cages at Different stocking Densities. Frontiers in Veterinary Science, 47(4), 1-7. https://doi.org/10.3389/fvets.2017.00047.

Gazoni, F. L. (2014). Prevalência de lesões intestinais por Eimeria nas empresas avícolas da região sul, Dissertação (Mestrado em Medicina Veterinária) Universidade Federalde Santa Maria, Rio Grande do Sul.

Gomes Filho, R., Juval, V., Teixeira, R. S. C., Lopes, E. S., Albuquerque, Á. H., Lima, S. V. G., Horn, R. V., Silva, R. C. R. \& Cardoso, W. M. (2014). Pesquisa de Salmonella spp. em galinhas criadas em fundo de quintal (Gallus gallus domesticus) e ovos comercializados nas feiras livres na cidade de Fortaleza, Ceará. Semina: Ciências Agrárias, 35(4), 1855-1864. 10.5433/1679-0359.2014v35n4p1855.

Hornink, G. G. \& Kawazoe. U. (2020). Coccidiose Aviária: Um parasito de galinha doméstica. Minas Gerais. Gabriel Gerber Hornink e-book Disponível em: http://www.unifal-mg.edu.br/bibliotecas/ebooks.

Hue, O., Le bouquin, S., Lalande, F., Allain, V., Rouxel, S., Petetin, I., Quesne, S., Laisney, M., Gloaguen, P., Picherot, M., Salvat, G., Bougeard, S. \& Chemaly, M. (2011). Prevalence of Salmonella spp. on broiler chicken carcasses and risk factors at the slaughterhouse in France in 2008. Food Control, 22(8), 1158-1164. https://doi.org/10.1016/j.fm.2010.11.003.

Kaboudi, K., Umar, S. \& Munir, M. T. (2016). Prevalence of Coccidiosis in Free-Range Chicken in Sidi Thabet, Tunisia. Hindawi Publishing Corporation Scientifica. 2016, 6. http://dx.doi.org/10.1155/2016/7075195

Luchese, F. C., Perinn, M., Aita, R.S., Mottin, V.D., Molento, M.B. \& Monteiro, SG. (2007). Prevalência de Espécies de Eimeria em Frangos de Criação Industrial e Alternativa. Braz. J. vet. Res. anim. Sci., 44(2), 81-86. https://doi.org/10.11606/issn.1678-4456.bjvras.2007.26645. 
Mapa (1999) - Ministério da Agricultura, Pecuária e Abastecimento. Departamento de Produtos de Origem Animal. Ofício circular, n007/ 1999. Registro de produto "frango caipira ou frango colonial" ou "frango tipo ou estilo caipira" ou "tipo ou estilo colonial". Diário Oficial. Brasília. 19 de maio de 2021, MINISTÉRIO DA AGRICULTURA E DO ABASTECIMENTO: https://www.agencia.cnptia.embrapa.br/Repositorio/Oficio-circular-7-de-19-de-maio-de1999_000gy48rvu302wx7ha0b6gs0xgpnhnya.pdf

Mapa (2012) - Ministério da Agricultura, Pecuária e Abastecimento. BRASIL. Departamento de Inspeção de Produtos de Origem Animal/ divisão de operações industriais. Ofício Circular DOI/DIPOA n ${ }^{\circ}$ 02/2012 de 01/02/2012. Registro do Produto "Frango Caipira ou Frango Colonial" ou "Frango Tipo ou Estilo Caipira" ou "Tipo ou Estilo Colonial". Brasília, DF. 19 de maio. Ministério da Agricultura e do Abastecimento. https://www.agencia.cnptia.embrapa.br/Repositorio/Oficio-circular-7-de-19-de-maio-de-1999_000gy48rvu302wx7ha0b6gs0xgpnhnya.pdf.

Morais, J.C. (2013). Diagnóstico de Eimeria spp. em frangos de corte na mesorregião sul do estado de Santa Catarina, por meio de multiplex PCR. Dissertação apresentada no programa de Pós-graduação em Ciência Animal do Centro de Ciências Agro veterinárias, da Universidade do Estado de Santa Catarina.

Morais, J., Ferreira, P. B., Jacome, I. M. T. D., Mello, R., Breda, F. C. \& Rorato, P. R. N. (2015). Curva de crescimento de diferentes linhagens de frango de corte caipira. Ciência Rural, 45(10), 1872-1878, http://dx.doi.org/10.1590/0103-8478cr20130867.

Pinheiro, B., DA Silva, A., Cavalcate, M., Mendonça, I. \& Conde Júnior, A. (2014). Coccidiose em Frangos de Produção. Revista Científica de Medicina Veterinária. Garça- São Paulo. Editora Faef.

Rossi, P. \& Bampi, G. B. (2015). Qualidade microbiológica de produtos de origem animal produzidos e comercializados no Oeste Catarinense. Segurança Alimentar E Nutricional, 22(2), 748-757. https://doi.org/10.20396/san.v22i2.8642505.

Santos, J. R., Meza, S. K. L., Martini, K. C. \& Nunes, R. V. (2013). A importância do controle da Salmonella na cadeia produtiva de frango de corte. Scientia Agraria Paranaensis - SAP Mal. Cdo. Rondon, 12(3), 167-174. 10.18188/1983-1471/sap.v12n3p167-174.

Silva, C. B. C., Chagas, W. F., Santos, R. F., Gomes, L. R., Ganda, M. R., \& Lima, A. M. C. (2015). Soroprevalência de Salmonella e Mycoplasma em frangos de corte comerciais, galinhas de fundo de quintal e galinhas gastas na região do Triângulo Mineiro, Estado de Minas Gerais, Brasil. Revista Brasileira de Ciência Avícola, 17 (1), 57-62. https://doi.org/10.1590/1516-635x170157-62.

Silva, A., Anjos, C., Nogueira, L., Ribeiro, A., \& Fraga, E. (2019). Salmonella spp. Um agente patogênico veiculado em alimentos. Encontro De ExtensãO, Docência E Iniciação Científica (EEDIC), 5(1). http://publicacoesacademicas.unicatolicaquixada.edu.br/index.php/eedic/article/view/3146 Sheather A. L. (1928). The detection of intestinal protozoa and mange parasites by a flotation technic. J. Comp. Ther.

Siqueira, G.B. (2016). Parasitos intestinais em galinhas caipiras da região metropolitana de Porto Alegre, RS. (Trabalho apresentado à Faculdade de Veterinária como requisito parcial à obtenção da graduação em Medicina Veterinária). Universidade Federal do Rio Grande do Sul, Faculdade de Veterinária, Porto Alegre.

Stella, A. E., Costa A. O., Ventura, G. F., Schimmunech, M. S., Lima, D. A. \& Paula, E. M. N. (2021). Salmonelose Aviária. Research, Society and Development, 10(4), e1910413835. http://dx.doi.org/10.33448/rsd-v10i4.13835.

Takahashi, S. E., Mendes, A. A., Saldanha, E. S. P. B., Pizollante, C. C., Pelícia, K., Garcia, R. G., Paz, I. C. L. A. \& Quinteiro, R. R. (2006). Efeito do sistema de criação sobre o desempenho e rendimento de carcaça de frangos de corte tipo colonial. Arq. Bras. Méd. Vet. Zootec., 58(4), 624-632. https://doi.org/10.1590/S0102-09352006000400026.

Wang, L. C., Zhang, T. T., Wen, C., Jiang, Z. Y., Wang, T., \& Zhou, Y. M. (2012). Protective effects of zinc-bearing clinoptilolite on broilers challenged withSalmonella pullorum. Poultry science, 91(8), 1838-1845. https://doi.org/10.3382/ps.2012-02284.

Yu, X., Yan, J., Zhu J., Wang, K., Xue, C., Zheng, X., Bi, Y. \& Xie, P. (2016). Riskassessment of Salmonella in broilerchicken. Wei Sheng Yan Jiu. Journal of Hygiene Research. https://europepmc.org/article/med/29903088. 